\title{
Prevalence of CYP2C19, CYP3A4 and FMO3 genetic polymorphisms in healthy northeastern Thai volunteers
}

\author{
Thikhumporn Areesinpitak, Sirimas Kanjanawart, Nontaya Nakkam, Wichittra Tassaneeyakul, \\ Suda Vannaphasaht*
}

Department of Pharmacology, Faculty of Medicine, Khon Kaen University, Khon Kaen 40002 Thailand

*Corresponding author, e-mail: sudvan@kku.ac.th

Received 13 Aug 2019

Accepted 23 May 2020

\begin{abstract}
Voriconazole is the first-line drug for invasive aspergillosis infection treatment. It is metabolized via cytochrome P450 2C19 (CYP2C19), cytochrome P450 3A4 (CYP3A4) and flavin-containing monooxygenase 3 (FMO3). Many studies revealed the correlation between genetic polymorphisms of these SNPs and voriconazole metabolism. Several mutations, however, have not been reported in Thai population. Therefore, this study investigated the prevalence of CYP2C19, CYP3A4 and FMO3 polymorphisms. Two hundred and forty-nine healthy northeastern Thai volunteers who were blood donors at Srinagarind Hospital blood bank were enrolled. CYP2C19 (*2, *3, *17), CYP3A4 (*22, rs4646437G>A) and FMO3 (rs2266782G>A, rs2266780A >G) mutations were investigated. The allele frequencies were CYP2C19*1 (0.72), *2 (0.24), *3 (0.03) and *17 (0.02) in this study. They were significantly different from Caucasian and Japanese populations. Moreover, CYP3A4 rs4646437 allele frequencies were 0.76 for " $G$ " and 0.24 for "A" alleles. The mutation of CYP3A4*22 was not found in this study. Wild type (G) and mutation (A) allele frequencies of FMO3 rs2266782 were 0.86 and 0.14, respectively. Similarly, the allele frequencies of FMO3 rs2266780 for "A" (wild type) and "G" (mutant) were 0.89 and 0.11 , respectively. Furthermore, a strong linkage disequilibrium was found between FMO3 rs2266782 and rs2266780 genes $\left(D^{\prime}=0.955, r^{2}=0.7021\right)$. The information on the SNP frequencies of CYP2C19, CYP3A4 and FMO3 in Thais was found to be significantly different from other populations. The genotype prevalence may be the preliminary information for a further clinical study to investigate the association between these genotypes and voriconazole treatment outcomes.
\end{abstract}

KEYWORDS: CYP2C19, CYP3A4, FMO3, polymorphisms, voriconazole

\section{INTRODUCTION}

Voriconazole is a triazole antifungal agent with high potency against severe fungal infections such as aspergillosis and resistant candidiasis. Voriconazole is metabolized mainly by CYP2C19 and partly by CYP3A4 and FMO3 [1-3]. Several studies reported genotype polymorphisms of these metabolizing enzymes correlated with voriconazole concentrations and dosage regimens. Voriconazole trough levels in poor metabolizers (PM) of CYP2C19 (CYP2C19*2/*2, CYP2C19*2/*3 and CYP2C19*3/*3) were significantly higher than those in the normal metabolizer (NM) group (CYP2C19*1/*1). Ultra-rapid metabolizer carriers (URM, CYP2C19*17/*17) had the lowest trough concentrations. Moreover, CYP2C19*17 carriers needed higher voriconazole dosage regimens to achieve the therapeutic range than NM and had a higher incidence of treatment failure than the wild type. In contrast, PM patients had to have lower voriconazole doses prescribed than NM to achieve the therapeutic range and had a higher rate of hepatotoxicity than NM [3-9].

Recently, forty-seven alleles of CYP2C19 genotype were reported. Nevertheless, only CYP2C19*2, CYP2C19*3 and CYP2C19*17 were the most common mutations in Asian populations [4, 6, 7, 9]. The CYP2C19*2; rs4244285, 681G $>$ A caused splicing defects leading to a decrease in enzyme activity. The CYP2C19*3; rs4986893, 636G $>$ A caused a premature stop codon resulting in non-enzyme activity. In contrast, CYP2C19*17; rs12248560, $-806 \mathrm{C}>\mathrm{T}$, $-3402 \mathrm{C}>\mathrm{T}$ created an increased transcription leading to high enzyme activity. Different phenotypes resulting from the mutations are divided into four groups. First, normal metabolizers have normal enzymatic activity and have the CYP2C19*1/*1 genotype. Second, CYP2C19*1/*2 or CYP2C19*1/*3 people are categorized into intermediate metabo- 
lizers (IM). The poor metabolizer group is for in dividuals with CYP2C19*2/*2, CYP2C19*2/*3 and CYP2C19*3/*3. People with the CYP2C19*17 alleles (CYP2C19*1/*17 or CYP2C19*17/*17) are classified as an ultra-rapid metabolizer. A previous Thai population study found the allele frequencies of CYP2C19*1, CYP2C19*2, CYP2C19*3 and CYP2C19*17 were $63,27,6$ and 4\%, respectively. The CYP2C19*2 allele frequency was similar to that of other Asian populations such as Japanese (29\%), Han-Chinese (37\%) and Korean (21\%), but was different from Caucasians. The frequency of the CYP2C19*3 in Thais was lower (6\%) than in Japanese and Korean populations (12\%) while no CYP2C19*3 allele was detected in Caucasians [10].

The mutation of CYP3A4 rs4646437 occurs at the 671-202 intron site of chromosome 7. The base changed from $\mathrm{G}$ to $\mathrm{A}$. The effect on CYP3A4 enzyme activity, however, is unclear. Shao et al $[8,11]$ revealed that CYP3A4 rs4646437 polymorphism was correlated with voriconazole trough concentration. The mutation of CYP3A4 rs4646437 affected an increase of voriconazole concentration. Following HapMap, mutant allele (A) frequency of CYP3A4 rs4646437 was $10-13 \%$ in Asians and Europeans, $25 \%$ in Hispanic and $60-90 \%$ in African American and African populations. No prevalence of this SNP, however, has been reported in Thais. CYP $3 A 4 * 22$ was another mutation of the CYP3A4 genotype that showed the correlation with voriconazole levels. This mutation leads to a decrease in CYP3A4 enzymatic activity due to the reduction of protein expression. Thus, voriconazole levels tended to rise in CYP3A4*22 carriers [5]. This allele mutation was found in $5-7 \%$ of the Caucasian population [12].

A previous in vitro study proposed that $25 \%$ of voriconazole was metabolized via FMO3 [3]. There is no study, however, indicating a correlation between $F M O 3$ polymorphism and voriconazole exposure. The mutation of FMO3 was found to affect human disease, metabolism and toxicity of other drugs. FMO3 variant alleles decreased enzyme activity [13]. Common variants of the FMO3 genotype were rs2266782 (E158K, 15167G $>A$, exon 4), rs2266780 (E308G, 21443A > G, exon 7) and rs1736557 (V257M, 18281G >A, exon 6) [13]. Following HapMap data, FMO3 rs2266782 allele frequencies in Caucasian and Asian populations were approximately $42 \%$ and $20 \%$, respectively. Moreover, FMO3 rs2266780 allele frequencies in Caucasian, Asian and African populations were approximately $22 \%, 18 \%$ and $1 \%$, respectively. Only $7.1 \%$ of FMO3 rs1736557 was found in Caucasian,
$14 \%$ in Asian and 2\% in African populations [14]. A previous study reported that the mutation of FMO3 rs1736557 presented a normal phenotype. It slightly reduced the enzyme activity in sulindac metabolism [13]. Another variant was FMO3 rs909530 (N285N, C> T, Exon 5), of which allele frequency was found in approximately $38 \%$ in Asian, $28 \%$ in European population and 54\% in African populations [14]. This mutant allele significantly decreased protein abundance [15].

In Thai population, the prevalence of CYP2C19 has been studied [10]. CYP3A4 and FMO3 mutations have not been reported. This study aimed to investigate the prevalence of CYP2C19, CYP3A4 and FMO3 genetic polymorphisms related to voriconazole metabolic pathway in healthy northeast Thai volunteers. Therefore, the prevalence of these genes would be the initial information to investigate further the association between genetic polymorphisms and voriconazole treatment in Thai population. The prevalence of these genotypes may be useful for the physicians to consider the significance of this mutation effecting voriconazole treatment in the future.

\section{MATERIALS AND METHODS}

\section{Subjects}

Two-hundred and forty-nine of healthy northeastern Thai volunteers were enrolled in this study at the Central Blood Bank, Srinagarind Hospital, Faculty of Medicine, Khon Kaen University. The volunteers were enrolled following two inclusion criteria. First, their age was more 18 years. Second, they are the northeastern Thais that were tested back to three generations. This study was carried out based on the Declaration of Helsinki and the ICH Good Clinical Practice Guidelines approved by the Ethics Committee for Human Research, Khon Kaen University (HE601155).

\section{DNA extraction and genotyping}

Three milliliters of blood were collected from each patient and then centrifuged to collect the buffy coat. The buffy coat was extracted by QIAamp ${ }^{\circledR}$ DNA Blood Mini Kits according to the manufacturer's instruction. The gDNA products were evaluated by using the NanoDrop. The purity of DNA was accepted in the range of $260 / 280$ at $1.8-2.0$. DNA concentration of the sample was more than $20 \mathrm{ng} / \mu \mathrm{l}$. The mutations were detected in all seven SNPs (CYP2C19*2, CYP2C19*3, CYP2C19*17, CYP3A4 rs4646437, CYP3A4*22, FMO3 rs2266782 
and FMO3 rs2266780). The genotyping was performed following TaqMan allelic discrimination assay by using the Light-Cycler 480 technology (Roche Diagnostics, Meylan, France) according to the manufacturer's instruction.

\section{Statistical analysis}

All frequencies were analyzed with the HardyWeinberg equilibrium on the Online Encyclopedia for Genetic Epidemiology studies web tool (OEGE) [16]. Pearson's Chi-square test or Fisher's exact test by SPSS was conducted to compare the differences in the prevalence of allele frequencies of the Thai population and other ethnicities. Linkage disequilibrium was calculated by the Cubic Exact Solution (CubeX) [17].

\section{RESULTS}

Results of CYP2C19 polymorphisms of two hundred and forty-nine northeastern Thai volunteers were summarized in Table 1 and Table 2. The allele frequencies were CYP2C19*1 (0.72), $* 2$ (0.24), $* 3(0.03)$ and $* 17(0.02)$ in this study. There were $51.4 \%(n=128)$ identified as CYP2C19*1/*1 (NM). Ninety-four volunteers $(37.8 \%)$ were identified as IM (CYP2C19 $* 1 / * 2$, $* 1 / * 3)$. PM (CYP2C19*2/*2,*2/*3) was found in $7.6 \%(n=19) . \quad$ CYP2C19*1/*17 was $2.4 \%$ $(n=6)$ and was categorized as URM. Moreover, CYP2C19*2/*17 was found in one volunteer $(0.8 \%)$. The allele frequencies of CYP2C19 in this study were significantly different from those of several ethnicities except for previous northeastern Thai studied and Chinese (Table 3).

One hundred and forty-seven volunteers (59\%) in this study were presented as the wild type allele (GG) of CYP3A4 rs4646437 while eighty six (34.6\%) of volunteers carried the heterozygous mutant (GA) of CYP3A4 rs4646437. The homozygous mutant (AA) of CYP3A4 rs4646437 was detected in sixteen volunteers $(6.4 \%)$. The allele frequencies of " $G$ " and "A" of CYP3A4 rs 4646437 were $76.3 \%(n=380)$

Table 1 CYP2C19 allele frequencies in healthy Thai volunteers.

\begin{tabular}{lcc}
\hline CYP2C19 & Number & Frequency \\
\hline$* 1$ & 356 & 0.71 \\
$* 2$ & 119 & 0.24 \\
$* 3$ & 15 & 0.03 \\
$* 17$ & 8 & 0.02 \\
\hline Total & 498 & 1.00 \\
\hline
\end{tabular}

Table 2 CYP2C19 genotype and phenotype frequencies in healthy northeastern Thai volunteers.

\begin{tabular}{|c|c|c|c|c|}
\hline \multirow{2}{*}{$\begin{array}{l}\text { Predicted } \\
\text { phenotype }^{\dagger}\end{array}$} & \multirow{2}{*}{ Genotype } & \multirow{2}{*}{ No. } & \multicolumn{2}{|c|}{ Frequency (\%) } \\
\hline & & & Genotype & Phenotype \\
\hline NM & $* 1 / * 1$ & 128 & 51.41 & 51.41 \\
\hline \multirow[t]{2}{*}{ IM } & $* 1 / * 2$ & 82 & 32.93 & 37.75 \\
\hline & $* 1 / * 3$ & 12 & 4.82 & \\
\hline \multirow[t]{2}{*}{ PM } & $* 2 / * 2$ & 16 & 6.43 & 7.63 \\
\hline & $* 2 / * 3$ & 3 & 1.20 & \\
\hline URM & $* 1 / * 17$ & 6 & 2.41 & 2.41 \\
\hline N/A & $* 2 / * 17$ & 2 & 0.80 & 0.80 \\
\hline Total & & 249 & 100 & 100 \\
\hline
\end{tabular}

and $23.7 \%$ ( $n=118)$, respectively. The frequencies were significantly different from both Asians and Caucasians (Table 4) $[11,18,19]$. The CYP3A4*22 mutant allele was not found in this study.

Genotype frequencies of FMO3 rs2266782 in this study were GG $73.5 \%(n=183)$, GA $25.3 \%$ $(n=64)$ and AA 1.2\% $(n=2)$ (Table 5). The allele frequencies of " $\mathrm{G}$ " and " $\mathrm{A}$ " in this study were $86.4 \%(n=430)$ and $13.6 \%(n=68)$, respectively. Furthermore, these were significantly different from Caucasians, African-Americans, Hispanics and Asians except for Koreans [20-23]. For FMO3 rs2266780 in this study, the genotype frequencies were $78.8 \%(n=196)$ for wild type (AA), $20.6 \%(n=52)$ for heterozygous mutant (AG) and $0.6 \%(n=1)$ for homozygous mutant (GG) (Table 6). There were $89.2 \%(n=444)$ for "A" allele and 10.8\% $(n=54)$ for "G" allele. FMO3 rs2266780 allele mutants were significantly different between Thais and Caucasians, African Americans and Asians. There was no significant difference between Thais and Hispanics [20-23]. All SNPs in this study were following the Hardy-Weinberg equilibrium $(p>0.05)$. Moreover, FMO3 rs2266780 and rs2266782 showed strong linkage disequilibrium $\left(D^{\prime}=0.955, r^{2}=0.7021\right)$.

\section{DISCUSSION}

Several previous studies reported the prevalence of CYP2C19 polymorphisms. Tassaneeyakul et al [24] first reported the prevalence in the northeastern Thai population of CYP2C19 in 2002. The result showed similar allele frequencies of CYP2C19 2 and CYP2C19*3 between Tassaneeyakul's study and this study. This similarity was because the subjects of 
Table 3 CYP2C19 allele frequencies from different ethnicities.

\begin{tabular}{|c|c|c|c|c|c|c|c|}
\hline \multirow[t]{2}{*}{ Ethnic group } & \multirow[t]{2}{*}{$n$} & \multicolumn{4}{|c|}{ CYP2C19 allele } & \multirow[t]{2}{*}{$p$-value } & \multirow[t]{2}{*}{ Ref. } \\
\hline & & $1 *$ & $2 *$ & $3 *$ & $17^{*}$ & & \\
\hline Northeastern Thai & 498 & 0.71 & 0.24 & 0.03 & 0.02 & & This study \\
\hline Northeastern Thai & 214 & 0.71 & 0.27 & 0.02 & NA & $0.247^{\mathrm{a}}$ & Tassaneeyakul [24] \\
\hline Thai & 2102 & 0.64 & 0.28 & 0.06 & 0.02 & $0.003^{\mathrm{a}}$ & Sukasem [10] \\
\hline Japanese & 530 & 0.58 & 0.28 & 0.13 & 0.01 & $<0.001^{\mathrm{a}}$ & Sugimoto [27] \\
\hline Korean & 200 & 0.65 & 0.25 & 0.08 & 0.02 & $0.032^{\mathrm{a}}$ & Myrand [26] \\
\hline Chinese & 200 & 0.67 & 0.29 & 0.03 & 0.01 & 0.342 & Myrand [26] \\
\hline Caucasian & 282 & 0.66 & 0.14 & - & 0.20 & $<0.001^{\mathrm{a}}$ & Myrand [26] \\
\hline Ugandan & 198 & 0.69 & 0.13 & 0.01 & 0.17 & $<0.001^{\mathrm{a}}$ & Miura [25] \\
\hline Russian & 1942 & 0.58 & 0.14 & 0.01 & 0.27 & $<0.001^{\mathrm{a}}$ & Sychev [28] \\
\hline
\end{tabular}

${ }^{\mathrm{a}}$ The mean difference is significant at the 0.050 level; $\mathrm{NA}=$ not available.

Table 4 CYP3A4 rs4646437 genotype and allele frequencies from different ethnicities.

\begin{tabular}{|c|c|c|c|c|c|c|c|c|}
\hline \multirow[t]{2}{*}{ Ethnic group } & \multirow[t]{2}{*}{$n$} & \multicolumn{3}{|c|}{ CYP3A4 (rs4646437) genotype (\%) } & \multicolumn{2}{|c|}{ Allele } & \multirow[t]{2}{*}{$p$-value } & \multirow[t]{2}{*}{ Ref. } \\
\hline & & GG & GA & AA & G & A & & \\
\hline Thai & 249 & $147(59.0)$ & $86(34.5)$ & $16(6.4)$ & 0.76 & 0.24 & & This study \\
\hline Chinese & 158 & $122(77.2)$ & $35(22.2)$ & $1(0.6)$ & 0.88 & 0.12 & $<0.001^{\mathrm{a}}$ & $\mathrm{He}[11]$ \\
\hline Japanese & 172 & $136(79.1)$ & $32(18.6)$ & $4(2.3)$ & 0.88 & 0.12 & $<0.001^{\mathrm{a}}$ & Hapmap \\
\hline Caucasian & 73 & $61(83.6)$ & $12(16.4)$ & $0(0.0)$ & 0.92 & 0.08 & $<0.001^{\mathrm{a}}$ & Crettol [18] \\
\hline Egyptian & 50 & $16(32.0)$ & $24(48.0)$ & $10(20.0)$ & 0.56 & 0.44 & $<0.001^{\mathrm{a}}$ & Sharaki [19] \\
\hline
\end{tabular}

a The mean difference is significant at the 0.050 level.

Table 5 FMO3 rs2266782 genotype and allele frequencies from different ethnicities.

\begin{tabular}{|c|c|c|c|c|c|c|c|c|}
\hline \multirow[t]{2}{*}{ Ethnic group } & \multirow[t]{2}{*}{$n$} & \multicolumn{3}{|c|}{ FMO3 (rs2266782, E158K) genotype (\%) } & \multicolumn{2}{|c|}{ Allele } & \multirow[t]{2}{*}{$p$-value } & \multirow[t]{2}{*}{ Ref. } \\
\hline & & GG & GA & AA & G & A & & \\
\hline Thai & 249 & $183(73.53)$ & $64(25.29)$ & $2(1.18)$ & 0.86 & 0.14 & & This study \\
\hline Han Chinese & 220 & $133(60.46)$ & $73(33.18)$ & $14(6.36)$ & 0.77 & 0.23 & $<0.001^{\mathrm{a}}$ & Ren [23] \\
\hline Korean & 219 & $147(67.12)$ & $61(27.86)$ & $11(5.02)$ & 0.81 & 0.19 & $0.028^{\mathrm{a}}$ & Park [22] \\
\hline Japanese & 172 & $108(62.79)$ & $52(30.23)$ & $12(6.98)$ & 0.78 & 0.22 & $0.001^{\mathrm{a}}$ & Hapmap \\
\hline Caucasian & 439 & $153(34.85)$ & 211 (48.07) & 75 (17.08) & 0.59 & 0.41 & $<0.001^{\mathrm{a}}$ & Наo [21] \\
\hline African-American & 328 & $103(31.40)$ & $160(48.78)$ & 65 (19.82) & 0.56 & 0.44 & $<0.001^{\mathrm{a}}$ & Нао [21] \\
\hline Hispanic & 85 & $36(42.35)$ & $38(44.71)$ & $11(12.94)$ & 0.65 & 0.35 & $<0.001^{\mathrm{a}}$ & Cashman [20] \\
\hline
\end{tabular}

${ }^{a}$ The mean difference is significant at the 0.050 level.

Table 6 FMO3 rs2266780 genotype and allele frequencies from different ethnicities.

\begin{tabular}{|c|c|c|c|c|c|c|c|c|}
\hline \multirow[t]{2}{*}{ Ethnic group } & \multirow[t]{2}{*}{$n$} & \multicolumn{3}{|c|}{ FMO3 (rs2266780, E308G) genotype (\%) } & \multicolumn{2}{|c|}{ Allele } & \multirow[t]{2}{*}{$p$-value } & \multirow[t]{2}{*}{ Ref. } \\
\hline & & GG & GA & AA & G & A & & \\
\hline Thai & 249 & $196(78.82)$ & $52(20.59)$ & $1(0.59)$ & 0.89 & 0.11 & & This study \\
\hline Han Chinese & 220 & $140(63.64)$ & $67(30.45)$ & $13(5.91)$ & 0.79 & 0.21 & $<0.001^{\mathrm{a}}$ & Ren [23] \\
\hline Korean & 219 & $149(68.04)$ & $60(27.40)$ & $10(4.56)$ & 0.82 & 0.18 & $0.001^{\mathrm{a}}$ & Park [22] \\
\hline Japanese & 172 & $114(66.28)$ & $50(29.07)$ & $8(4.65)$ & 0.81 & 0.19 & $0.001^{\mathrm{a}}$ & Hapmap \\
\hline Caucasian & 231 & $159(68.83)$ & $63(27.27)$ & $9(3.90)$ & 0.82 & 0.18 & $0.003^{\mathrm{a}}$ & Нao [21] \\
\hline African-American & 328 & 305 (92.99) & $22(6.71)$ & $1(0.30)$ & 0.96 & 0.04 & $<0.001^{\mathrm{a}}$ & Наo [21] \\
\hline Hispanic & 85 & $66(77.65)$ & $17(20.00)$ & $2(2.35)$ & 0.88 & 0.12 & 0.590 & Cashman [20] \\
\hline
\end{tabular}

\footnotetext{
a The mean difference is significant at the 0.050 level.
} 
both studies were from the same native area. However, the study of Tassaneeyakul et al [24] did not determine the allele frequency of $C Y P 2 C 19 * 17$. The CYP2C19 allele frequencies in this study were significantly different from Sukasem's study and other studies in Japanese, Caucasian, Ugandan and Russian populations [10,25-28]. No difference in allele frequencies was found among other Asians such as Chinese and Korean [26]. Differences of CYP2C19 allele frequencies among the Thai population may be due to the different regions of subject origins between this study and Sukasem's study [10]. In this study, volunteers were enrolled from the northeastern of Thailand while the origins of the volunteers of Sukasem's report were not described [10]. The CYP2C19*3 allele frequency of northeastern Thais was two-fold lower than that of Sukasem's study.

CYP3A4 rs4646437 was another SNP that was published influencing voriconazole plasma concentrations in Chinese $[8,11]$. In this study, the mutant allele (A) frequency of CYP3A4 rs4646437 was different from other ethnicities. The Thai population had a higher allele frequency of "A" allele than either Asians or Caucasians (24\%, 12\% and 8\%, respectively) [8]. Therefore, CYP3A4 rs4646437 mutation might play an important role in voriconazole metabolism in Thai patients.

Many publications revealed the correlation between the mutations of the FMO3 gene and the fishodor syndrome and other drug responses [13]. The previous study reported that the mutation of the gene encoding FMO3 enzyme might affect voriconazole metabolism and play a role of up to $20 \%$ [3]. In the Thai population, the $F M O 3$ allele frequency was not reported. Therefore, FMO3 rs2266782 and rs2266780 that had been reported for the association was selected to be determined in Thais. In this overview, both SNPs frequencies were significantly different from Asians, Caucasians, African Americans and Hispanics. FMO3 rs2266782 in Thais showed a lower frequency than in other ethnic populations. Yamazaki and Shimizu [14] revealed that the mutation of FMO3 rs2266782 coincided with the mutation of FMO3 rs2266780, causing more interruption of the enzyme function. Linkage disequilibrium (LD) was found between FMO3 rs2266782 and rs2266780 in this study $\left(D^{\prime}=0.955\right.$, $\left.r^{2}=0.7021\right)$. Likewise, the LD of these two SNPs was displayed in other Asian populations such as Chinese $\left(D^{\prime}=0.977, r^{2}=0.944\right)$ and Korean $\left(D^{\prime}=\right.$ $0.969, r^{2}=0.897$ ) [29]. However, the linkage in Chinese was stronger than in Korean and this study, suggesting that the linkage was variable among the populations. In contrast, there was no LD report of these SNPs in other ethnic groups.

In conclusion, the prevalence differences of CYP2C19, CYP3A4 and FMO3 polymorphisms of the Thai population from many ethnicities may lead to variations in the voriconazole dosage regimens, risk of toxicity and therapeutic outcomes. Therefore, we are investigating the association between CYP2C19, CYP3A4 and FMO3 polymorphisms and voriconazole concentration, clinical outcome and toxicity, respectively, in Thais.

Acknowledgements: The authors sincerely thank all staff at Central Blood Bank, Srinagarind Hospital, Faculty of Medicine, Khon Kaen University, for supporting this research. Miss Thikhumporn Areesinpitak was supported by the Research Fund for supporting lecturer to admit high potential students to study and research on his expert program year 2015, the grant of Graduate School, Khon Kaen University. This study was supported by Thailand Science Research and Innovation (TSRI) (RSA6180028). We would like to acknowledge James A. Will, Emeritus Professor, University of Wisconsin-Madison for editing the manuscript via Publication Clinic KKU, Thailand.

\section{REFERENCES}

1. Hyland R, Jones BC, Smith DA (2003) Identification of the cytochrome P450 enzymes involved in the $N$-oxidation of voriconazole. Drug Metab Dispos 31, 540-547.

2. Roffey SJ, Cole S, Comby P, Gibson D, Jezequel SG, Nedderman ANR, Smith DA, Walker DK, et al (2003) The disposition of voriconazole in mouse, rat, rabbit, guinea pig, dog and human. Drug Metab Dispos 31, 731-741.

3. Yanni SB, Annaert PP, Augustijns P, Bridges A, Gao Y, Benjamin DK, Thakker DR (2008) Role of flavincontaining monooxygenase in oxidative metabolism of voriconazole by human liver microsomes. Drug Metab Dispos 36, 1119-1125.

4. Chuwongwattana S, Jantararoungtong T, Chitasombat MN, Puangpetch A, Prommas S, Dilokpattanamongkol P, Watcharananan SP, Sukasem C (2016) A prospective observational study of CYP2C19 polymorphisms and voriconazole plasma level in adult Thai patients with invasive aspergillosis. Drug Metab Pharmacokinet 31, 117-122.

5. Gautier-Veyret E, Fonrose X, Tonini J, ThiebautBertrand A, Bartoli M, Quesada JL, Bulabois CE, Cahn JY, et al (2015) Variability of voriconazole plasma concentrations after allogeneic hematopoietic stem cell transplantation: impact of cytochrome p450 polymorphisms and comedications on initial and subsequent trough levels. Antimicrob Agents Chemother 59, 2305-2314. 
6. Lamoureux F, Duflot T, Woillard JB, Metsu D, Pereira $\mathrm{T}$, Compagnon P, Morisse-Pradier H, El Kholy M, et al (2016) Impact of CYP2C19 genetic polymorphisms on voriconazole dosing and exposure in adult patients with invasive fungal infections. Int $J$ Antimicrob Agents 47, 124-131.

7. Scholz I, Oberwittler H, Riedel KD, Burhenne J, Weiss J, Haefeli WE, Mikus G (2009) Pharmacokinetics, metabolism and bioavailability of the triazole antifungal agent voriconazole in relation to CYP2C19 genotype. Br J Clin Pharmacol 68, 906-915.

8. Shao B, Ma Y, Li Q, Wang Y, Zhu Z, Zhao H, Sun J, Dong L, et al (2017) Effects of cytochrome P450 3A4 and non-genetic factors on initial voriconazole serum trough concentrations in hematological patients with different cytochrome P450 2C19 genotypes. Xenobiotica $47,1121-1129$.

9. Wang G, Lei HP, Li Z, Tan ZR, Guo D, Fan L, Chen Y, Hu DL, et al (2009) The CYP2C19 ultra-rapid metabolizer genotype influences the pharmacokinetics of voriconazole in healthy male volunteers. Eur J Clin Pharmacol 65, 281-285.

10. Sukasem C, Tunthong R, Chamnanphon M, Santon S, Jantararoungtong T, Koomdee N, Prommas S, Puangpetch A, et al (2013) CYP2C19 polymorphisms in the Thai population and the clinical response to clopidogrel in patients with atherothrombotic-risk factors. Pharmgenomics Pers Med 6, 85-91.

11. He HR, Sun JY, Ren XD, Wang TT, Zhai YJ, Chen SY, Dong YL, Lu J (2015) Effects of CYP3A4 polymorphisms on the plasma concentration of voriconazole. Eur J Clin Microbiol Infect Dis 34, 811-819.

12. Elens L, Gelder T, Gelder DA, Haufroid V, Schaik RHN (2013) CYP3A4*22: promising newly identified CYP3A4 variant allele for personalizing pharmacotherapy. Pharmacogenomics 14, 47-62.

13. Motika MS, Zhang J, Cashman JR (2007) Flavincontaining monooxygenase 3 and human disease. Expert Opin Drug Metab Toxicol 3, 831-845.

14. Yamazaki H, Shimizu M (2013) Survey of variants of human flavin-containing monooxygenase 3 (FMO3) and their drug oxidation activities. Biochem Pharmacol 85, 1588-1593.

15. Xu M, Bhatt DK, Yeung CK, Claw KG, Chaudhry AS, Gaedigk A, Pearce RE, Broeckel U, et al (2017) Genetic and nongenetic factors associated with protein abundance of flavin-containing monooxygenase 3 in human liver. $J$ Pharmacol Exp Ther 363, 265-274.

16. Rodriguez S, Gaunt TR, Day INM (2009) HardyWeinberg equilibrium testing of biological ascertainment for Mendelian randomization studies. Am $J$ Epidemiol 169, 505-514.

17. Gaunt TR, Rodriguez S, Day INM (2007) Cubic exact solutions for the estimation of pairwise haplotype frequencies: implications for linkage disequilibrium analyses and a web tool 'CubeX'. BMC Bioinformatics 8, ID 1.
18. Crettol S, Venetz J, Fontana M, Aubert J, Pascual M, Eap CB (2008) CYP3A7, CYP3A5, CYP $3 A 4$, and $A B C B 1$ genetic polymorphisms, cyclosporine concentration, and dose requirement in transplant recipients. Ther Drug Monit 30, 689-699.

19. Sharaki O, Zeid M, Moez P, Zakaria NH, Nassar E (2015) Impact of CYP3A4 and MDR1 gene (G2677T) polymorphisms on dose requirement of the cyclosporine in renal transplant Egyptian recipients. Mol Biol Rep 42, 105-117.

20. Cashman JR, Zhang J, Leushner J, Braun A (2001) Population distribution of human flavin-containing monooxygenase form 3: gene polymorphisms. Drug Metab Dispos 29, 1629-1637.

21. Hao DC, Sun J, Furnes B, Schlenk D, Li MX, Yang SL, Yang L (2007) Allele and genotype frequencies of polymorphic FMO3 gene in two genetically distinct populations. Cell Biochem Funct 25, 443-453.

22. Park CS, Kang JH, Chung WG, Yi HG, Pie JE, Park DK, Hines RN, McCarver DG, et al (2002) Ethnic differences in allelic frequency of two favin-containing monooxygenase 3 (FMO3) polymorphisms: linkage and effects on in vivo and in vitro FMO activities. Pharmacogenetics 12, 77-80.

23. Ren L, Teng M, Zhang T, Zhang X, Sun B, Qin S, Zhong L, Peng Z, et al (2017) Donors FMO3 polymorphisms affect tacrolimus elimination in Chinese liver transplant patients. Pharmacogenomics 18, 265-275.

24. Tassaneeyakul W, Tawalee A, Kukongviriyapan V, Blaisdell J, Goldstein JA, Gaysornsiri D (2002) Analysis of the CYP2C19 polymorphism in a North-eastern Thai population. Pharmacogenetics 12, 221-225.

25. Miura J, Obua C, Abbo C, Kaneko S, Tateishi T (2009) Cytochrome P450 $2 C 19$ genetic polymorphisms in Ugandans. Eur J Clin Pharmacol 65, 319-320.

26. Myrand SP, Sekiguchi K, Man MZ, Lin X, Tzeng RY, Teng CH, Hee B, Garrett M, et al (2008) Pharmacokinetics/genotype associations for major cytochrome P450 enzymes in native and first- and third-generation Japanese populations: comparison with Korean, Chinese, and Caucasian populations. Clin Pharmacol Ther 84, 347-361.

27. Sugimoto K, Uno T, Yamazaki H, Tateishi T (2008) Limited frequency of the CYP2C19*17 allele and its minor role in a Japanese population. $\mathrm{Br} J$ Clin Pharmacol 65, 437-439.

28. Sychev DA, Denisenko NP, Sizova ZM, Grachev AV, Velikolug KA (2015) The frequency of CYP2C19 genetic polymorphisms in Russian patients with peptic ulcers treated with proton pump inhibitors. Pharmgenomics Pers Med 8, 111-114.

29. Zhou LP, Tan ZR, Chen H, Guo D, Chen Y, Huang WH, Wang LS, Zhang GG (2014) Effect of two-linked mutations of the FMO3 gene on itopride metabolism in Chinese healthy volunteers. Eur J Clin Pharmacol 70, 1333-1338. 